\title{
Adsorption Studies of Copper on Rice Husk Ash (RHA)
}

\author{
Sumra Naeem, *Naseem Zahra and Uzma Zafar \\ PCSIR Laboratotres Complex, Lahore,Pakistan
}

\begin{abstract}
In present investigation the adsorption of copper on rice husk ash was studied by using batch technique. The quantities of copper metal before and after the treatment of their standard solutions with rice husk ash were determined by atomic absorption spectrophotometer. Percentage adsorption was calculated for RHA-Copper solution system. The effects of various parameters, such as pH of solution, contact time, temperature and adsorbate concentration were studied. It was observed that adsorption of copper increased with increasing time, temperature, $\mathrm{pH}$ and decreased with increasing adsorbate concentration. Adsorption process is interpreted in terms of Freundlich equation. It was found that rice husk ash can be used as a suitable adsorbent for the removal of copper from wastewater.
\end{abstract}

Key words: Adsorption, Copper, Rice husk ash

\section{Introduction}

Pollution of heavy metals is of major concern in developing countries. The discharge of heavy metals into water- courses is a serious pollution problem which may affect the quality of water supply. Increasing concentration of these metals in the water constitute a severe health hazard due to their nondegradability and toxicity. Copper metal considered in this project is a widely used material. Copper metal contamination exists in aqueous waste streams from many industries such as electronic and electrical, metal plating, mining, manufacture of computer heat sinks, Cu plumbing as well as biostatic surface, as a component in ceramic glazing and glass coloring. Copper is persistent, bioaccumulative and toxic metal that does not readily breakdown in the environment and is not easily metabolized. It may accumulate in human ecological food chain through consumption or uptake and may be hazardous to human health. Drinking water that contains higher than normal levels of copper may cause vomiting, diarrhea, stomach cramp and nausea. The chronic effects of consumption of high levels copper are kidney and liver damage. The suggested safe level of copper in drinking water for humans varies depending on the sources, but tends to be pegged at 1.5 to $2.0 \mathrm{mg} / \mathrm{L}$. Hence removal of copper from water and wastewaters assumes important (Nauja et al. 2008). The effects of various parameters, such as $\mathrm{pH}$ of the feed solution, contact time, temperature, adsorbate and adsorbent concentrations, and particle size of the adsorbent, were studied for optimization of the process parameters. The adsorption behavior of $\mathrm{Cu}$ on three solid waste materials-sea nodule residue (SNR), fly ash (FA), and red mud (RM) was observed (Agrawal et al. 2004). It was noted that adsorption of copper increased with increasing time, temperature, $\mathrm{pH}$,

\footnotetext{
* Corresponding author: E-mail:
}

and adsorbate concentration, and decreased with increasing initial copper concentration. The ability of rice husk ash to remove chromium, zinc, copper and cadmium from waste water has been investigated. Several parameters that can affect metals uptake such as particle size, $\mathrm{pH}$ and temperature were described. At the optimal conditions, the chromium, zinc, copper and cadmium ions removal from aqueous solution are 79, 85, 80 and 85\%, respectively. After the adsorption of metal ions, the analyte retained in the husk could be recovered almost completely by eluting with dilute hydrochloric acid solution (Munaf et al. 1997). Rice husk was studied as a potential scavenger of lead from various aqueous solutions. Physiochemical parameters such as selection of appropriate electrolyte, shaking time, and the concentrations of adsorbent and adsorbate were studied for the decontamination of effluents using a batch technique (Nasir et al. 1998). The utility of rice husk ash as an adsorbent for metal ions such as iron, zinc and copper from acid mine water was assessed. Study of Chockalingam et al. 2006 revealed that about $99 \% \mathrm{Fe}^{3+}, 98 \%$ of $\mathrm{Fe}^{2+}$ and $\mathrm{Zn}^{2+}$ and 95\% $\mathrm{Cu}^{2+}$ uptake was achieved from acid mine water, with increase in $\mathrm{pH}$ value by two units using rice husk. Batch studies were conducted by Mohan et al. 2008 to find out the optimum dose of adsorbent, optimal $\mathrm{pH}$ and contact time for individual metal solution, both with rice husk $(\mathrm{RH})$ and phosphate treated rice husk $(\mathrm{PRH})$. The equilibrium was achieved after 30 minutes for $\mathrm{Pb}, 40$ minutes for $\mathrm{Cu}$ and 50 minutes both for $\mathrm{Zn}$ and $\mathrm{Mn}$ and the maximum removal efficiency was attained at a $\mathrm{pH}$ of 6 for $\mathrm{Pb}, \mathrm{pH}$ of 7 for $\mathrm{Zn}, \mathrm{Cu}$ and $\mathrm{Mn}$ for the single metal solutions. Adsorption of copper (II), silver (I), oxalate (II) and ferrocyanide (IV) has been 
studied (Rameshwar et al.1962) by various samples of hydrous thorium oxide at different temperatures. Increase in temperature leads to the decrease in the adsorptive capacity of the hydroxide. Orange peel, sawdust and bagasse have been used as adsorbents for the removal of $\mathrm{Cu}$ (II) from aqueous solution and the effects of contact time, $\mathrm{pH}$, concentration, dose and ionic strength on the removal of $\mathrm{Cu}$ (II) have been studied. Moreover, treated sawdust has been used as an adsorbent for the same. The equilibrium adsorption capacity of the adsorbents for $\mathrm{Cu}$ (II) was obtained by Langmuir isotherm (Ahsan et al. 2007). The ionic strength effect on the removal of $\mathrm{Cu}$ (II) from its aqueous solution indicated that the removal followed ion-exchange mechanism. Adsorption is interpreted in terms of Freundlich and Langmuir equations (Sumra et al. 2009).

In the present study rice husk ash (RHA), prepared form rice husk incineration was used for the removal of copper from aqueous solution synthetically prepared in the laboratory.

\section{Materials and Method}

\section{Reagents}

All reagents used in the experimental work were of analytical grade (E.MERCK) TM, the following chemicals were employed: 1000ppm $\mathrm{CuSO}_{4} \cdot 5 \mathrm{H}_{2} \mathrm{O}$ Stock solution. Various standard solutions were prepared by taking a known aliquot of the stock solution in borosilicate $250 \mathrm{ml}$ measuring flasks, making the volume up to the mark with deionized water.

\section{Adsorbent preparation}

RHA was prepared from rice husk ash (which was obtained from Daroghewala Rice Mills, Lahore) by incineration at $750^{\circ} \mathrm{C}$ in Muffle furnace (Make: PCSIR, 2005). By heating at $750^{\circ} \mathrm{C}$ a carbon free sample of ash was obtained, which was ground to -200 mesh and was used without any chemical treatment for the adsorption studies reported here.

\section{Instrumentation}

Atomic absorption spectrometer "Hitachi Polarized Zeeman AAS" equipped with standard burner and air-acetylene flame was used to determine the concentration of copper in each filtrate. The hollow-cathode lamp of copper metal was used.

\section{Procedure}

The adsorption of $\mathrm{Cu}^{+2}$ on rice husk ash was studied by batch-technique. All parameters were studied at pH 7.2 and were measured by using pH meter (Model: 8417 Hanna Instruments). To study the effect of $\mathrm{pH}$ on adsorption, in one set of experiment $\mathrm{pH}$ of the suspensions were adjusted by using $\mathrm{NH}_{4} \mathrm{OH}$ and $\mathrm{HNO}_{3}$. The ratio of aqueous solution to adsorbent was 50:1. Adsorption of $\mathrm{Cu}^{+2}$ on rice husk ash was determined in terms of percentage extraction by AAS.

\section{Results and Discussion}

In this study, the batch adsorption process was used in order to remove copper from water by rice husk ash as adsorbent. The adsorption of $\mathrm{Cu}^{+2}$ on the rice husk ash (RHA) was studied as a function of shaking time, $\mathrm{pH}$, adsorbate concentration and temperature for known $\mathrm{Cu}^{+2}$ concentrations. The quantity of copper in wastewater after adsorption on rice husk ash sample was determined by AAS. A complete chemical analysis of rice husk ash is given in Table I.

Table I: Chemical Analysis of Rice Husk Ash

\begin{tabular}{c|c}
\hline Metal Oxides & \% age \\
\hline $\mathrm{SiO}_{2}$ & 94.7520 \\
$\mathrm{Fe}_{2} \mathrm{O}_{3}$ & 0.9000 \\
$\mathrm{MgO}$ & 0.6400 \\
$\mathrm{CaO}$ & 0.4980 \\
$\mathrm{Na}_{2} \mathrm{O}$ & 1.0852 \\
$\mathrm{~K}_{2} \mathrm{O}$ & 2.0300 \\
\hline
\end{tabular}

\section{1-Effect of time on adsorption}

Copper solution of 100 ppm was used in order to study the effect of time for copper adsorption. Adsorption of copper on rice husk ash as a function of time was determined and equilibrium was established after 30 minutes (Namasivayam et

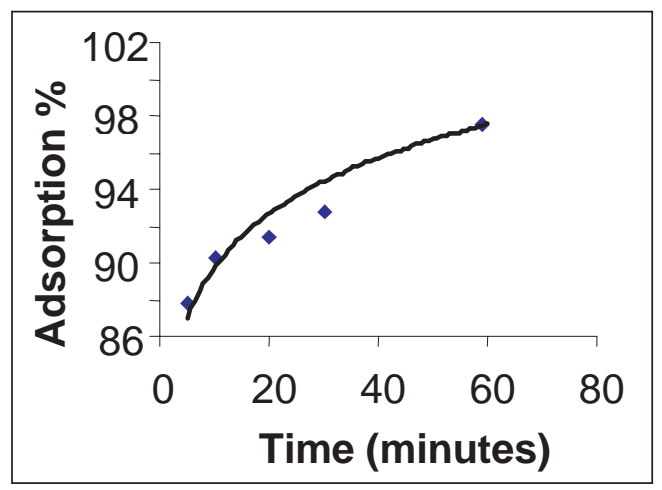

Fig. 1: Effect of Time on Adsorption of Copper on Rice Husk Ash

al. 1995). The effects of contact time on the amount of metal ions on adsorbent surface are shown in Fig. 1. It reveals that the curves are smooth and continuous, leading to saturation, suggesting the possible monolayer coverage of the metal ions on rice husk ash surface. Once again there is not a significant change of amount of metal ion adsorbed with time, which give an indication of ion exchange mechanism.

\section{2-Effect of concentration of copper on adsorption}

Effect of concentration of copper ions on adsorption using rice husk ash was studied by varying the initial concentration of copper solutions (60-120ppm). Percentage adsorption of 
copper decreases with increasing metal concentration (Namasivayam et al. 1996) which suggest that at least two types of phenomena (i.e. adsorption as well as ion exchange) taking place in the range of metal concentration studied. In addition less favorable lattice positions or exchange sites become involved with increasing metal concentration.

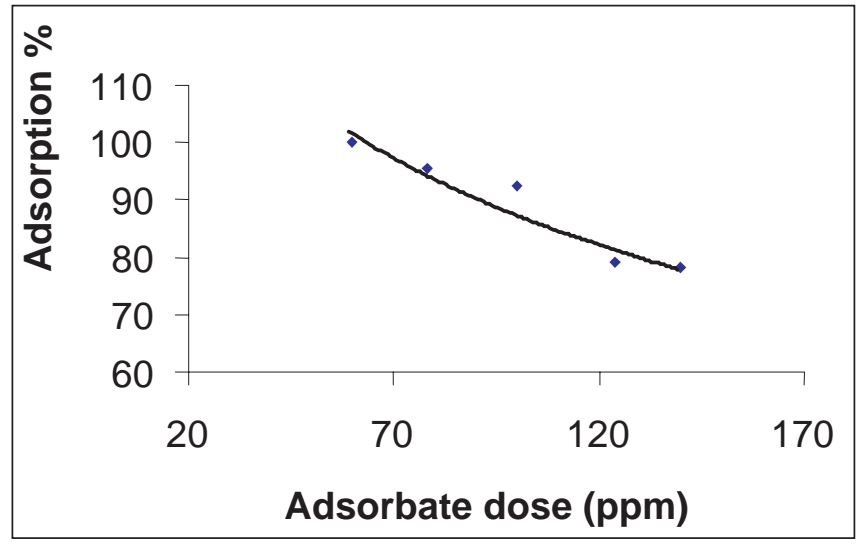

Fig. 2: Effect of Adsorbate dose on Adsorption of Copper on Rice Husk Ash

\section{4-Effect of pH on adsorption}

The acidity of solution $\mathrm{pH}$ is one of the most important parameters controlling the uptake of heavy metals from wastewater and aqueous solutions. The uptake and percentage removal of copper from the aqueous solution are strongly affected by the $\mathrm{pH}$ of the solution. The adsorption of copper increases when $\mathrm{pH}$ increases from 2 to 6 . After that the capacity of adsorption decreases in $\mathrm{pH}$ range of 7 to 9.The minimum adsorption observed at low $\mathrm{pH}(\mathrm{pH} 2)$ may be due to the fact that the higher concentration and higher mobility of $\mathrm{H}^{+}$ions present favored the preferential adsorption of hydrogen ions compared to $\mathrm{Cu}$ (II) ions. It would be plausi- ble to suggest that at lower $\mathrm{pH}$ value, the surface of the adsorbent is surrounded by hydronium ions $(\mathrm{H}+)$, thereby preventing the metal ions from approaching the binding sites of sorbent (Wong et al. 2003). As the $\mathrm{pH}$ increases, more negatively charged surface becomes available thus facilitating greater copper removal. It is commonly agreed that the sorption of metal cations increases with increasing $\mathrm{pH}$ as the metal ionic species become less stable in the solution. It is found that maximum adsorption is observed at $\mathrm{pH} 2$ and 8 (Fig. 3).

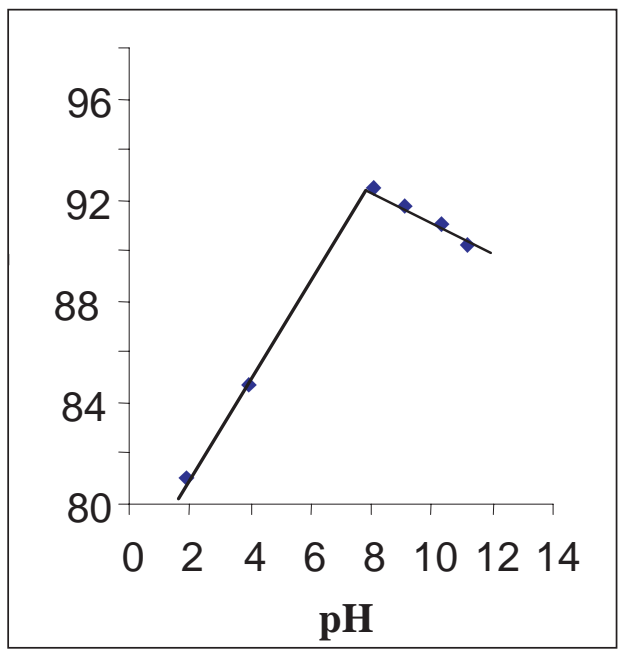

Fig. 3: Effect of pH on Adsorption of Copper on Rice Husk Ash

\section{4-Effect of temperature on adsorption}

Effect of temperature on copper adsorption was observed. Three concentrations of Cu soln. (100, 120, 140 ppm) were studied at four different temperature ranges (20, 40, 60, $80^{\circ} \mathrm{C}$ ). Adsorption of $\mathrm{Cu}^{+2}$ increases with increasing temperature (Fig. 4). The adsorption isotherms at four different

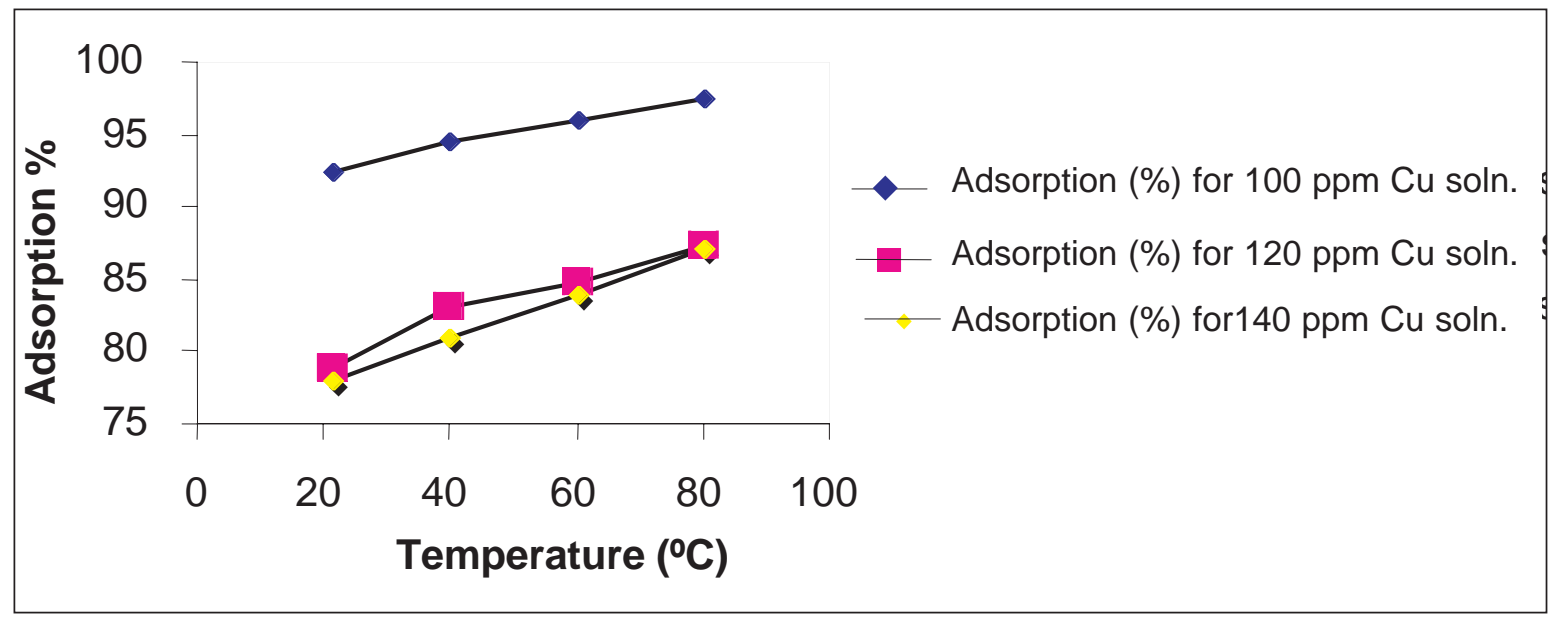

Fig. 4: Effect of Temperature on Adsorption of Copper solutions (100,120,140 ppm) on Rice Husk Ash 
temperatures $\left(20 \pm 0.5{ }^{\circ} \mathrm{C}, \quad 40 \pm 0.5{ }^{\circ} \mathrm{C}, \quad 60 \pm 0.5{ }^{\circ} \mathrm{C}\right.$ and $80+0.5^{\circ} \mathrm{C}$ ) were obtained by plotting the amount of Copper adsorbed on RHA (g/g) against metal at equilibrium concentration (Fig.5). The straight lines were obtained for Freundlich isotherms which gave the comparable values of Freundlich constants (Sumra et al. 2009). The Freundlich isotherm (Saad et al. 1994, Sarwar et al. 1994) describes the adsorption according to the following relationship:

$\left(C_{0}-C\right) / m=K C^{1 / n}$

Where, $C_{0}=$ the initial conc. of copper ions in solution; $C=$ the conc. of copper ions where the equilibrium was reached; $m=$ the amount of rice husk ash used $(\mathrm{g} / 100 \mathrm{ml}) ; k$ and $n=$ empirical constants. When $\log \left(C_{0^{-}} C\right) / m$ was plotted against $\log C$, a straight line was found, showing that the Freundlich equation is satisfied.

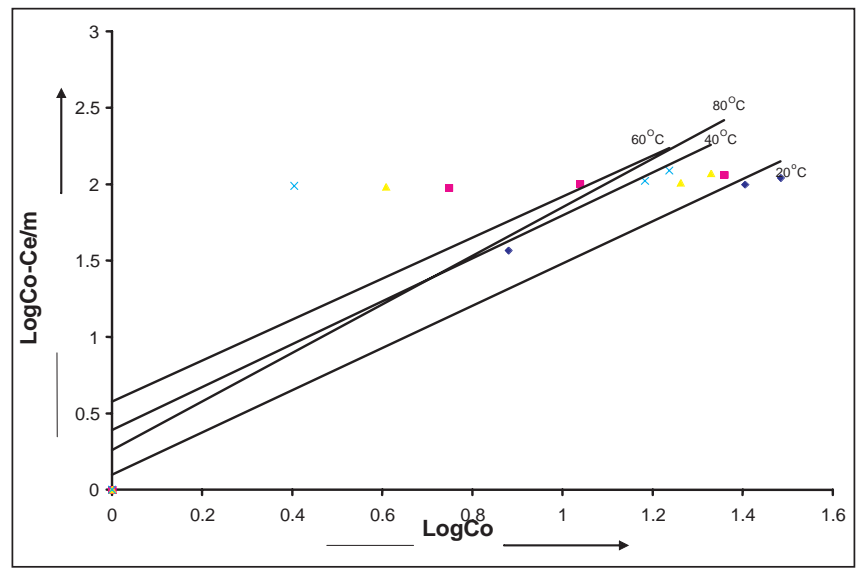

Fig. 5: Freundlich Adsorption Isotherms for Copper on Rice Husk Ash at Different Temperatures

\section{Conclusion}

A number of methods for toxic metal removal from waste water have been used, but most have several disadvantages, such as continuous input of chemicals, high cost, toxic sludge generation or incomplete metal removal. The use of rice husk ash not only provides a less costly sorbent to activated carbon or synthetic ion-exchanger but also available in abundant quantity.

\section{References}

Agrawal A., Sahu K. K., Pandey B. D. (2004). A comparative adsorption study of copper on various industrial solid wastes, AIChE journal, 50: 2430-2438.

Ahsan H., Islam N., Islam A. and Shafiqul Alam A. M. (2007). Removal of copper from aqueous solution using orange peel, sawdust and bagasse. Pak. J. Anal. Environ. Chem., 8:21- 25.
Chockalingam E. and Subramanian S. (2006). Studies on removal of metal ions and sulphate reduction using rice husk and desulfotomaculum nigrificans with reference to remediation of acid mine drainage, Chemosphere, 62: 699-708.

Mohan S., Gandhimathi R. and Sreelakshmi G. (2008). Isotherm studies for heavy metal adsorption on rice husk. Asian Journal of Water, 5: 71-78.

Munaf E, Zein R. (1997). The use of rice husk for removal of toxic metals from waste water, Environmental technology, 18: 359-362.

Nasir K., Shujaat A., Seema N. K. and Jamil A. (1998). Removal of lead from aqueous solutions using rice husk, Separation Science and Technology, 33: 2349 2362.

Nauja D. T., Luqman A., Zawani Z. and Abdul Rasheed S. (2008). Adsorption of copper from aqueous solution by Elais Guineensis Kernal Activated Carbon, Journal of Engineering Science and Technology, 3:180-189.

Rameshwar P. and Arun K. (1962). Effect of temperature on the adsorption of Copper (II), Silver (I), Oxalate (II) and Ferrocyanide (IV) by different samples of precipitated hydrous thorium oxide. Colloid \& Polymer Science, 183: 71-74.

Saad A. K., Riaz U. R. and Ali M. A. (1994). Sorption of cesium on bentonite, Waste management, 12: 125-137.

Sarwar M. and Sumra N. (1994). Adsorption studies of gold on copper sulphide. Hydrometallurgy, 36: 385-391.

Wong K. K., Lee C. K., Low K. S. and Haron M. J. (2003). Removal of $\mathrm{Cu}$ and $\mathrm{Pb}$ by tartaric acid modified rice husk from aqueous Solutions. Chemosphere, 50: 23-28.

Sumra N., Uzma Z., Arifa A., Asma I. (2009). Adsorption studies of Cr (VI) on Rice Husk Ash. J. Chem. Soc. Pak., 31: 379-382.

Namasivayam C. and Yamuna R. T. (1995). Adsorption of Direct Red by Biogas Residual Slurry. Environ. Pollut. 89:1.

Namasivayam C., Muniasamy N., Gayathri K., Rani M. and Renganathan K. (1996). Removal of Dyes from Aqueous Solution by Cellulosic Waste Orange Peel. Biores. Technol., 57: 37.

Received : June 11, 2009;

Accepted : January 26, 2010 